\title{
EFFECT OF GLUCOSE CONCENTRATION IN THE GROWTH MEDIUM UPON NEUTRAL AND ACIDIC FERMENTATION END-PRODUCTS OF CLOSTRIDIUM BIFERMENTANS, CLOSTRIDIUM SPOROGENES AND PEPTOSTREPTOCOCCUS ANAEROBIUS
}

\author{
L. J. Turton, ${ }^{*}$ D. B. Drucker and L. A. Ganguli
}

Microbiology Laboratory, Hope Hospital, Salford, M6 8HD, and *Department of Bacteriology and Virology, University of Manchester, Manchester M13 9PT.

Summary. Clostridium bifermentans, C. sporogenes and Peptostreptococcus anaerobius were grown in Fastidious Anaerobe Broth with glucose concentrations from $0-1 \cdot 5 \%(\mathrm{w} / \mathrm{v})$. Gas chromatographic (GLC) analysis of fermentation end-products revealed that a change in glucose concentration markedly affected fermentation patterns of each microorganism. Increased glucose concentration resulted in stimulation of ethanol production by all strains, and of butanol and butyric acid by $C$. sporogenes. With $C$. bifermentans, there was a parallel increase in ethanol and acetic acid production and decreased formation of propanol and propionic, iso-butyric and iso-valeric acids. Increased ethanol formation by $P$. anaerobius was accompanied by an increase in acetic acid and a decrease in butan-1-ol production. The greatest incremental change in GLC profiles occurred when glucose concentration was raised from zero to $0 \cdot 1 \%(\mathrm{w} / \mathrm{v})$. These data suggest that glucose concentration in a medium for GLC analysis must be rigorously controlled if reproducible results are to be obtained.

\section{INTRODUCTION}

Gas chromatographic techniques for assisting classification and identification of microorganisms of clinical significance are now well documented. Such methods are usually based upon analysis of whole cell pyrolysates, specific structural components of cells, or fermentation end-products (Drucker, 1981). Analysis of fermentation end-products of anaerobes has been described in detail by Holdeman, Cato and Moore (1977) and is a routine procedure in many clinical laboratories. The success of fermentation product analysis depends upon the ability of different anaerobes to produce characteristic end-products, in a reproducible manner (Brooks, 1977). Fermentation end-products are formed in primary energy-yielding metabolism and, therefore, ought to be susceptible to modification by catabolite repression of enzyme synthesis, or by modification of enzyme activity (McGilvery, 1979). Fermentation profiles have been shown to be modified by medium composition or incubation time (Mayhew and Gorbach, 1975), by haemin for members of the Bacteroidaceae (Lindner 
and Marcelis, 1978), or by fermentable carbohydrate (Lombard, 1979). Glucose is of particular significance in that it may react with other medium constituents; it may also be converted into other metabolic effectors. Saccharolytic organisms preferentially metabolise glucose rather than amino acids, producing straight-chain acids and alcohols. To determine whether glucose concentration in media needs to be rigorously controlled we have examined the effect of different concentrations in Fastidious Anaerobe Broth on the fermentation profiles of three anaerobes.

\section{MATERIALS AND METHODS}

Bacteria. Clostridium bifermentans strain NCTC506 and C. sporogenes strain NCTC532 were obtained from the National Collection of Type Cultures (NCTC), Central PHLS Laboratory, Colindale Avenue, London NW9 5HT. Peptostreptococcus anaerobius strain ATCC27337 was obtained from the American Type Culture Collection (ATCC), 12301 Parklawn Drive, Rockville, MD 20852, U.S.A. The anaerobes were characterised on the basis of morphology in gram-stained smears, fermentation pattern (Holdeman et al., 1977) after growth in cooked meat medium (Lab-m Ltd, Ford Lane, Salford), and result profile in API 20A (API Ltd, Farnborough, Hants; Hauser and Zabransky, 1976). Additional tests used for $P$. anaerobius were sensitivity to novobiocin (Wren, Eldon and Dakin, 1977) and liquoid (Wideman et al., 1976); API 20A was not used for this organism.

Culture media. The media for fermentation end-product analysis were prepared from Fastidious Anaerobe Broth (FAB; Lab-m). The concentration of glucose in this broth was determined by UV enzymic assay (Boehringer Mannheim, Mannheim, W. Germany). FAB was dispensed in 28-ml glass bottles and supplemented with $\mathrm{D}$-glucose (BDH, Poole, Dorset) to give final concentrations of $0,0 \cdot 1,0 \cdot 2,0 \cdot 3,0 \cdot 4,0 \cdot 5,0 \cdot 6,0 \cdot 7,0 \cdot 8,0 \cdot 9,1 \cdot 0$ and $1 \cdot 5 \%(w / v)$. Bottles were autoclaved at $121^{\circ} \mathrm{C}$ for $15 \mathrm{~min}$ with the caps loose.

\section{Gas chromatography (GLC)}

For each strain, triplicate series of 28-ml bottles of FAB were seeded with one drop of culture from cooked-meat medium incubated at $37^{\circ} \mathrm{C}$ for $48 \mathrm{~h}$. FAB cultures were incubated at $37^{\circ} \mathrm{C}$ for $72 \mathrm{~h}$, then smears were stained by Gram's method. The cultures were centrifuged and 10-ml of supernatant fluid was acidified with $0.4 \mathrm{ml} 50 \%(\mathrm{w} / \mathrm{v})$ sulphuric acid containing heptanoic acid $1 \mathrm{meq} / 100 \mathrm{ml}$ as an internal standard. Duplicate ether extractions for GLC analysis were made of all acidified cultures, by mixing $1 \mathrm{ml}$ of culture with $1 \mathrm{ml}$ diethyl ether (Analar; BDH Ltd) after salting-out alcohols with $0.4 \mathrm{~g} \mathrm{NaCl}$ (Analar).

Ether extracts $(2 \mu \mathrm{l})$ were injected on to a $1.84 \mathrm{~m} \times 4 \mathrm{~mm}$ I.D. glass column of Carbowax $20 \mathrm{M}$ TPA $6 \%$ on Gas Chrom Q (60-80 mesh) obtained from Phase Separations Ltd, Queensferry, Clwyd. The injections were made with an S8 Autoinjector (Pye Unicam Ltd, Cambridge) and the dual columns were operated in a Pye Unicam 204 gas chromatograph equipped with a Flame Ionisation Detector. Injection temperature was $150^{\circ} \mathrm{C}$, detector oven temperature was $250^{\circ} \mathrm{C}$; column oven temperature was programmed from $60-160^{\circ} \mathrm{C}$ at a rate of $8^{\circ} \mathrm{min}$, with a final hold of $8 \mathrm{~min}$. Nitrogen flow rate was $40 \mathrm{ml} / \mathrm{min}$; the flow rate for air was $600 \mathrm{ml} / \mathrm{min}$ and for hydrogen $40 \mathrm{ml} / \mathrm{min}$. Resultant peaks were integrated using a model 304-50 integrator (Infotronics, Stone, Staffordshire) and the traces recorded on a 10-mV model PM8252 recorder (Phillips, Eindhoven, Netherlands).

For each alcohol and acid of interest, a calibration graph was prepared by extraction and analysis of aqueous solutions of standards by the same methods as the supernatant fluids. Stock solutions of standard alcohols and acids were prepared as described by Holdeman et al. (1977) and diluted to give solutions of $0,0 \cdot 1,0 \cdot 2,0 \cdot 5,1 \cdot 0,2 \cdot 0,3 \cdot 5$ and $5.0 \mathrm{meq} / 100 \mathrm{ml}$ for analysis.

\section{RESULTS}

The patterns of fermentation end-products of all three strains of bacteria varied 

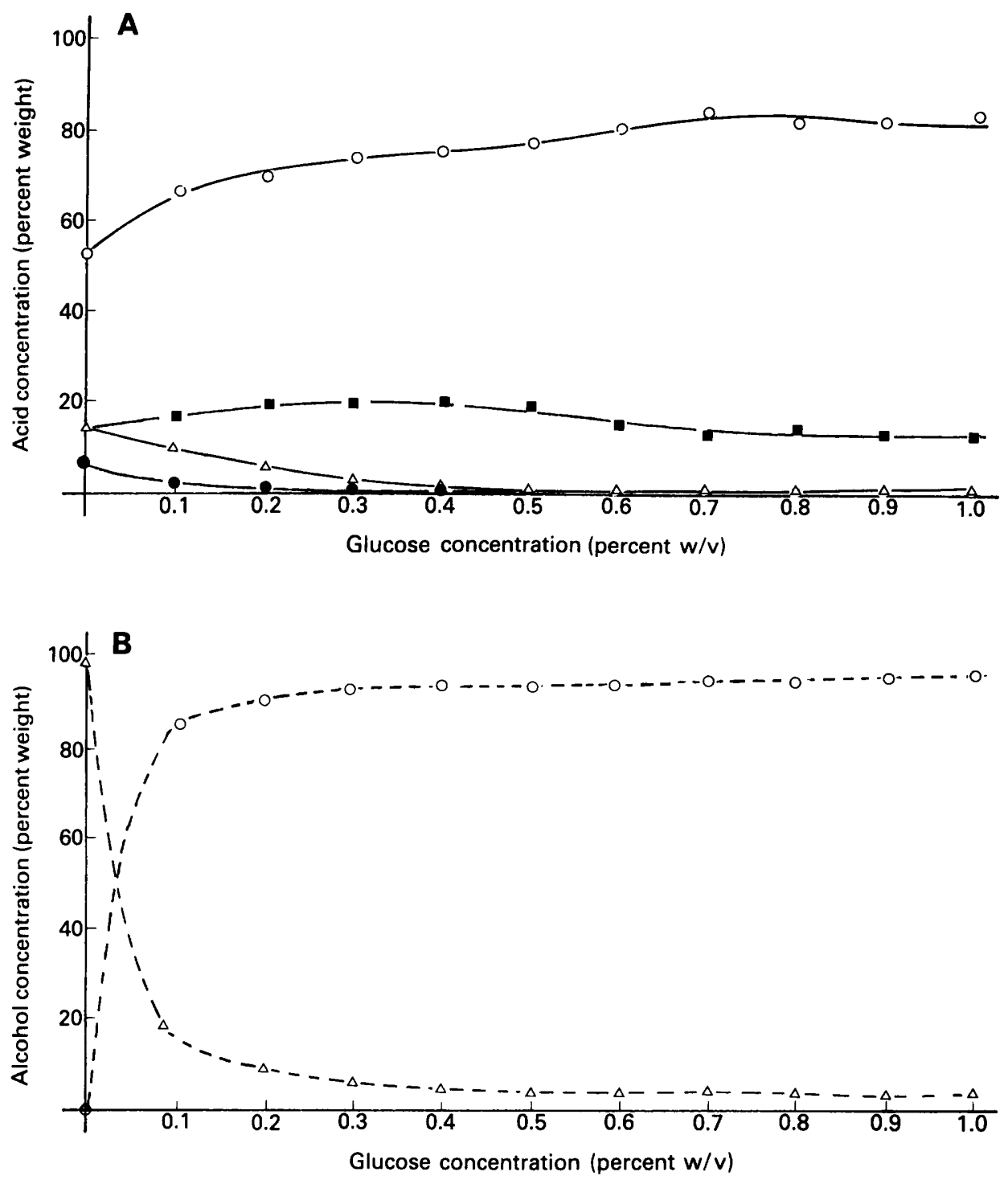

FIG. 1.-Effect of glucose concentration upon (A) volatile acids and (B) alcohols of C. bifermentans grown in Fastidious Anaerobe Broth (FAB). $\mathrm{O}-\mathrm{O}=$ acetic acid; $\Delta-\Delta=$ propionic acid; $-\longrightarrow=i$ isobutyric acid; $-=$ iso-caproic acid; $O---O=$ ethanol; $\Delta---\Delta=$ propanol

directly with glucose concentration in FAB; the maximum effect occurred between $0 \cdot 1-0 \cdot 4 \%(\mathrm{w} / \mathrm{v})$. C. bifermentans produced more acetic acid relative to other acids (fig. 1A) and the ratio of ethanol to propanol was markedly increased when the glucose concentration was raised to $0 \cdot 1 \%$ (w/v) (fig. 1B). These modified profiles were very evident when the gas chromatograms were inspected. With $C$. sporogenes, the alterations in amounts of acetic and butyric acids were particularly obvious (fig. 2A). Such changes were mirrored by alterations in proportions of the corresponding straight chain alcohols, ethanol and butan-1-ol (fig. 2B). P. anaerobius also produced 

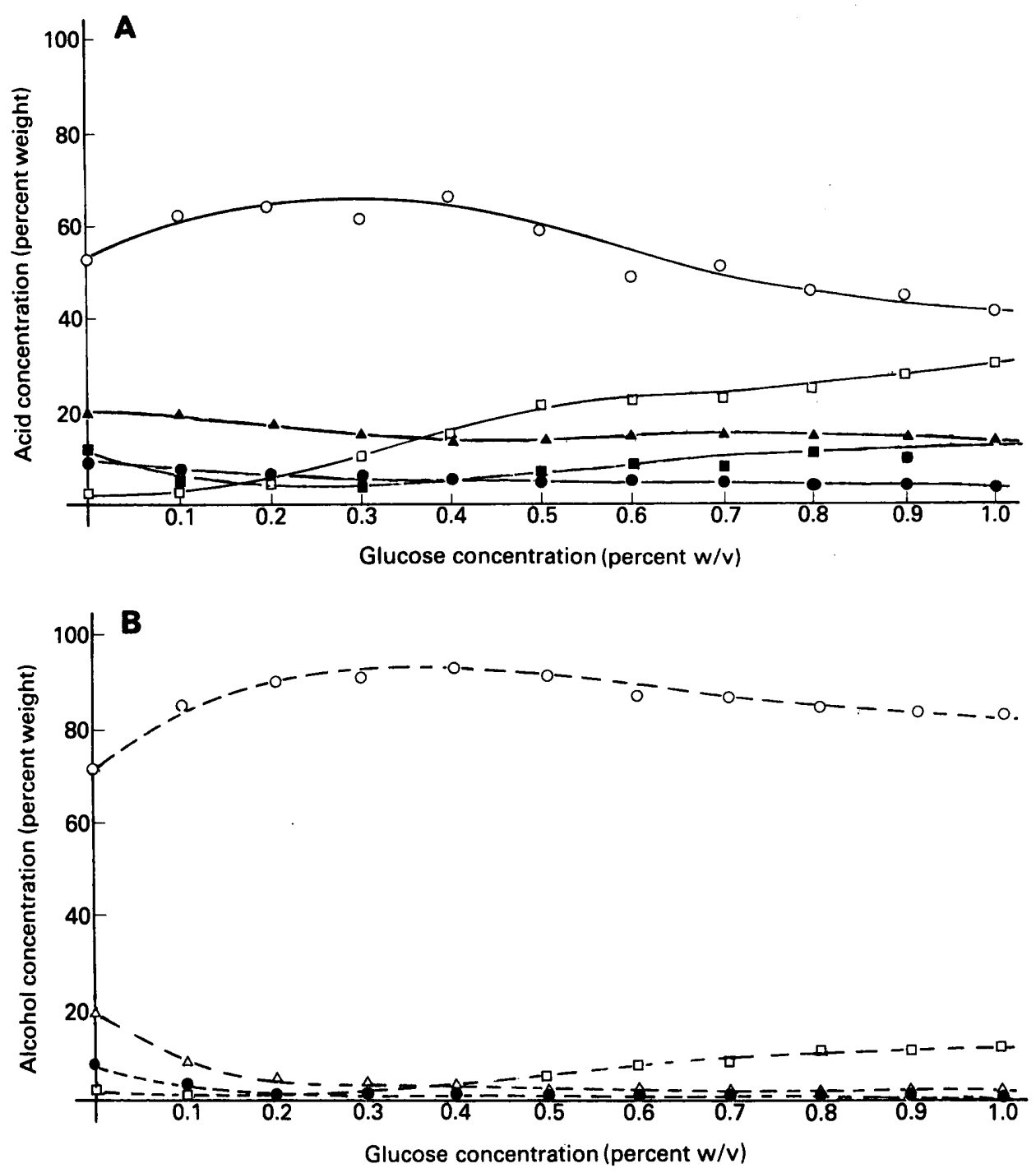

Fig. 2.-Effect of glucose concentration upon (A) volatile acids and (B) alcohols of $C$. sporogenes grown in FAB. $\mathrm{O} \longrightarrow \mathrm{O}=$ acetic acid; $\square-\square=$ butyric acid; $\longrightarrow=$ iso-butyric acid; $O--O=$ ethanol; $\Delta---\Delta=$ propanol; $\bullet---\bullet=$ iso-butanol; $\square---\square=$ butan-1-ol.

more acetic acid relative to other acids as glucose concentration was increased (fig. 3A). There was an associated increase of the corresponding alcohol, ethanol (fig. 3B) with a fall in the proportion of butan-1-ol to a very low level in FAB that contained as little as $0.1 \%$ glucose $(w / v)$. Coefficients of variation for each peak analysed indicated that experimental variation was very low; values ranged from $1-6 \%$ acetic acid produced by C. bifermentans in the various glucose concentrations.

\section{Discussion}

The effects observed with $C$. bifermentans indicate the considerable influence of 

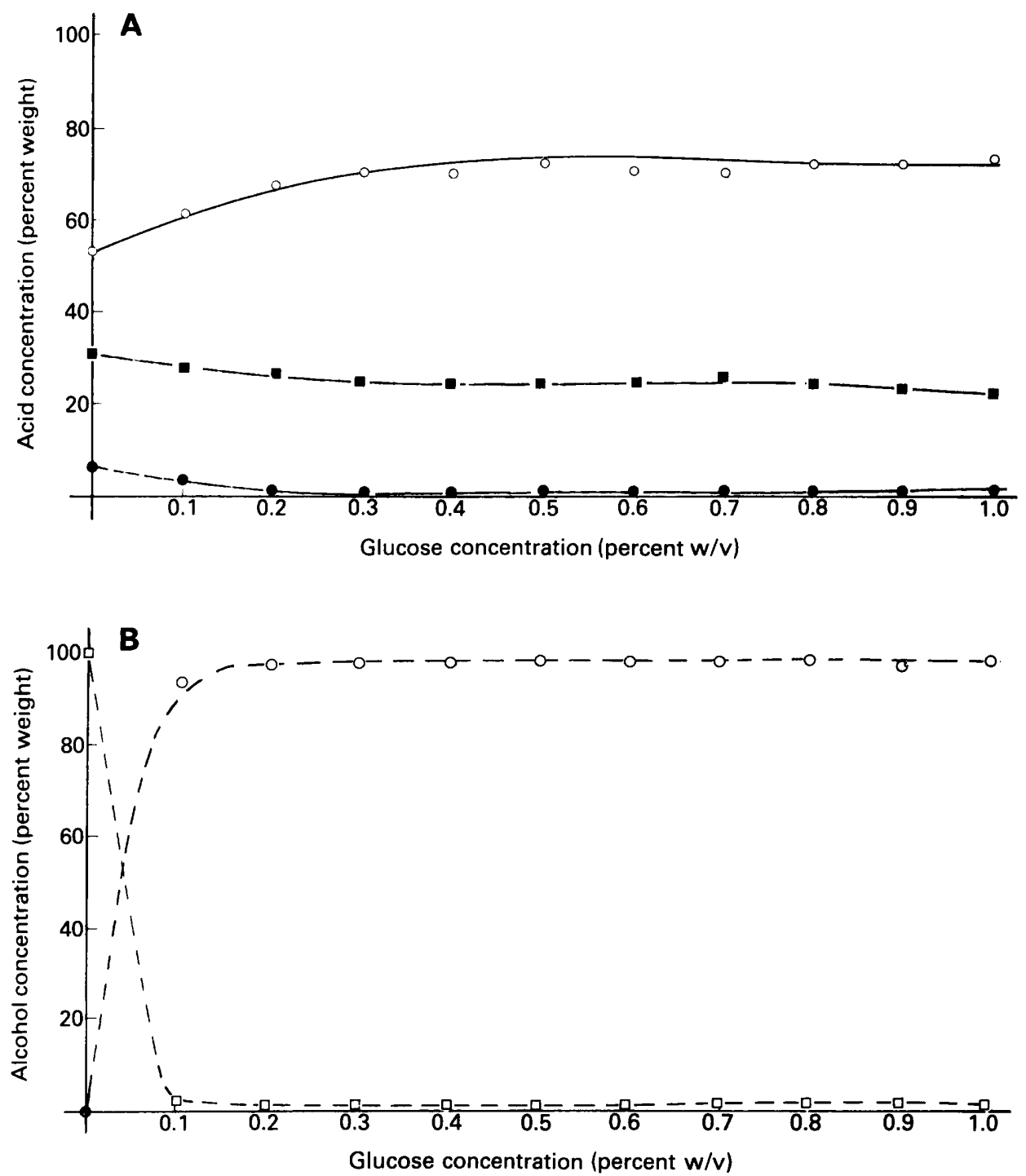

FIG. 3.-Effect of glucose concentration upon (A) volatile acids and (B) alcohols of $P$. anaerobius grown in $\mathrm{FAB} . \mathrm{O}-\mathrm{O}=$ acetic acid; $\longrightarrow=$ iso-butyric acid; $\square-\mathbf{\square}=i$ iso-caproic acid; $\mathrm{O}---\mathrm{O}=$ ethanol; ㅁ- - $\square=$ butan-1-ol.

glucose concentration on end products. With raised glucose, both acetic acid and ethanol concentrations rise. The latter compounds are produced as alternative 2-carbon fermentation products. If the cell's ratio of NAD ${ }^{+}: \mathrm{NADH}$ is decreased, it may be restored by reduction of acetyl-CoA to ethanol; otherwise formation of acetic acid will permit synthesis of ATP (Doelle, 1969). Production of branched chain acids and alcohols arises primarily from reductive deamination of iso-leucine, leucine and valine (Elsden and Hilton, 1978). Deamination may be inhibited by glucose, being replaced by decarboxylation following a fall in $p \mathrm{H}$.

Similar biochemical arguments may be applied to the data obtained with $C$. 
sporogenes. With this organism, increase in glucose concentration stimulates an increase in the proportions of acetic and butyric acids and of ethanol and butan-1-ol. Acetic and butyric acids can both arise from catabolism of histidine or cysteine (Loesche and Gibbons, 1968), threonine (Elsden and Hilton, 1978), aspartate or lysine (Stadtman, 1963) or glutamate (Buckel and Barker, 1974). However, acetic acid can also arise from glucose via pyruvate. Similarly, butyric acid can readily be formed from acetyl-CoA derived from pyruvate. Two acetyl residues are condensed to yield acetoacetyl-CoA which undergoes $\beta$-reduction to butyric acid and ultimately to butan-1-ol.

The interpretation of data for $P$. anaerobius is slightly complicated by the many different effects of glucose upon microorganisms, e.g., inhibition of growth (Shanson, 1978), reduction in viability (Ganguli, Turton and Tillotson, 1982), and modification of biomass and enzyme production (Greenman, Holland and Cunliffe, 1981). Acetic acid and ethanol are proportionately increased by glucose but butan-1-ol formation is suppressed. Even in the absence of glucose, little butyric acid was found. The source of butan-1-ol is not clear. The production of iso-caproic acid in all concentrations of glucose possibly indicates constitutive enzymes for catabolism of leucine or iso-leucine (Elsden and Hilton, 1978).

The relevance of the above findings for the diagnostic laboratory is that glucose concentrations in commercial media range from as little as $0.01 \mathrm{~g} / \mathrm{L}$ in FAB to $10 \mathrm{~g} / \mathrm{L}$ in Peptone Yeast-Extract Glucose Broth. When cooked meat media of four different manufacturers were recently analysed, the glucose concentrations ranged from $0.02-0.58 \mathrm{~g} / \mathrm{L}$ (unpublished data). Such variations would result in major quantitative differences in fermentation profiles with any of the anaerobes examined in this study. One solution would be to use a medium with a very low glucose content, e.g., FAB. Another solution would be to follow the practice of the VPI anaerobe laboratory and use media containing $1 \%(\mathrm{w} / \mathrm{v})$ glucose (Holdeman et al., 1977); at this level trace amounts in medium constituents are unlikely to have a significant effect upon the total concentration of glucose available. The two disadvantages of the latter approach are the lethal effects of excess glucose for some anaerobes and a possible inhibition of catabolism of amino acids to yield branched chain alcohols and acids.

\section{REFERENCES}

BRoOKs, J. B. 1977. Detection of bacterial metabolites in spent culture media and body fluids by electron capture gas-liquid chromatography. Advances in Chromatography, 15, 1-31.

BUCKEL, W. AND BARKER, H. A. 1974. Two pathways of glutamate fermentation by anaerobic bacteria. Journal of Bacteriology, 117, 1248-1260.

Doelle, H. W. 1969. Bacterial metabolism. Academic Press, London, p. 101.

DruCKer, D. B. 1981. Microbiological Applications of Gas Chromatography. Cambridge University Press, Cambridge, pp. 60-131.

ElsDen, S. R. AND Hilton, M. G. 1978. Volatile acid production from threonine, valine, leucine and iso-leucine by clostridia. Archives of Microbiology, 117, 165-172.

Ganguli, L. A., Turton, L. J. and Tillotson, G. S. 1982. Evaluation of Fastidious Anaerobe Broth as a blood culture medium. Journal of clinical Pathology, 35, 458-461.

Greenman, J., Holland, K. T. AND CUnLIFFe, W. J. 1981. Effects of glucose concentration on biomass, maximum specific growth rate and extracellular enzyme production by three species of cutaneous propionibacteria grown in continuous culture. Journal of General Microbiology, 127, 371-376.

HAUSER, K. J. AND ZABRANSKY, R. J. 1976. Evaluation of the API anaerobe system (API 20A) 
for the identification of anaerobes in a clinical laboratory. Abstracts of the Annual Meeting of the American Society for Microbiology, 28.

Holdeman, L. V., Cato, E. P. AND Moore, W. E. C. 1977. Anaerobe laboratory manual, 4th ed., VPI Anaerobe Laboratory, Blacksburg, VA.

LINDNER, J. G. E. M. AND MARCELIS, J. H. 1978. Quantitative gas chromatography of Bacteroides species under different growth conditions. Antonie van Leeuwenhoek, 44, 1-14.

Loesche, W. J. AND GibBons, R. J. 1968. Amino acid fermentation by Fusobacterium nucleatum. Archives of Oral Biology, 13, 191-201.

LOMBARD, G. L. 1979. The effect of growth medium composition on the elaboration of metabolic acids detected by gas-liquid chromatography of anaerobic bacteria. Abstracts of the Annual Meeting of the American Society for Microbiology, 332.

MCGILVERY, R. W. 1979. Biochemistry-a functional approach, 2nd ed., Holt-Saunders, Philadelphia, p. 296.

MAYHEW, J. W. AND GoRBaCh, S. L. 1975. Rapid gas chromatographic technique for presumptive detection of Clostridium botulinum in contaminated food. Applied Microbiology, 29, 297-299.

Shanson, D. C. 1978. Blood culture techniques. In Modern topics in infection, edited by J. D. Williams, Heinemann, London, p. 14.

Stadtman, T. C. 1963. Anaerobic degradation of lysine. II. Cofactor requirements and properties of the soluble enzyme system. Journal of Biological Chemistry, 238, 2766-2773.

Wideman, P. A., VARgo, V. L. Citronbaum, D. AND Finegold, S. M. 1976. Evaluation of the sodium polyanethol sulphonate disc test for the identification of Peptostreptococcus anaerobius. Journal of Clinical Microbiology, 4, 330-333.

Wren, M. W. D., Eldon, C. P. AND Dakin, G. H. 1977. Novobiocin and the differentiation of peptococci and peptostreptococci. Journal of Clinical Pathology, 30, 620-622. 